\title{
Successful education for AEC professionals: case study of applying immersive game-like virtual reality interfaces
}

\author{
Farzad Pour Rahimian ${ }^{1 *}$, Tomasz Arciszewski ${ }^{2}$ and Jack Steven Goulding ${ }^{1}$
}

\begin{abstract}
Background: Global competition and the transdisciplinary nature of evolving Architecture-EngineeringConstruction (AEC) activities makes it progressively important to educate new AEC professionals with appropriate skill sets. These skills include the ability and capability of not only developing routine projects, but also delivering novel design solutions and construction processes (some of which may be unknown), to feasible, surprising, or potentially patentable solutions. For example, despite recent innovations in immersive visualisation technologies and tele-presence decision-support toolkits, the AEC sector as a whole has not yet fully understood these technologies, nor embraced them as an enabler.
\end{abstract}

Methods: Given this, this paper proposes a new approach for delivering education and training to address this shortcoming. This approach focuses on doing traditional (routine) work with creative thinking in order to address these challenges. This rationale is based on the principles of Successful Education as a new paradigm for engineering education, which is inspired by the Theory of Successful Intelligence, by the Medici Effect and Leonardo da Vinci's Seven Principles. The paper presents the educating AEC professionals is presented the AEC sector. The Theory of Successful Intelligence and its three forms of intelligence (Practical, Analytical, and Creative), are supported by lessons learned from the Renaissance, including the Medici Effect and da Vinci's Seven Principles.

Results: Based on these theoretical pillars, a new approach to educating AEC professionals is presented with a proof-of-concept prototype that uses a game-like virtual reality (VR) visualisation interface supported by Mind Mapping is introduced as an exemplar.

Conclusion: The developed interface in this study applies Game Theory to non-collocated design teams in accordance with Social Sciences Theory (social rules) and Behavioural Science Theory (decision making). It contributes by supporting new insights into AEC actor involvement, pedagogy, organisational behaviour, and the social constructs that support decision making.

Keywords: Training; Successful education; Pedagogy; Medici effect; da Vinci Principles; Visualisation

\section{Background}

The Architecture-Engineering-Construction (AEC) sector is one of the largest industrial employers in many countries. In the European Union (EU) for example, it encompasses more than 2 million enterprises and approximately 12 million employees, representing 9.8\% of the EU's Gross Domestic Product and employing over $7.1 \%$ of the

\footnotetext{
* Correspondence: fpour-rahimian@uclan.ac.uk

'Centre for Sustainable Development, The Grenfell-Baines School of Architecture, Construction and Environment, University of Central Lancashire, Preston PR1 2HE, UK

Full list of author information is available at the end of the article
}

workforce (NGRF 2010). This contribution and global competition makes the novelty of the AEC projects increasingly important. Therefore, AEC professionals need to be educated how to develop not only traditional, or routine projects, but also projects incorporating novel designs and construction processes. They need to be creative, and be able to develop unknown (or unproven) solutions which are feasible, surprising, and potentially patentable. Currently, AEC professionals are no longer being seen as leaders or innovators, more followers - using deductive problem solving rather than seeking opportunities, using

\section{实 Springer}

(c) 2014 Pour Rahimian et al.; licensee Springer. This is an Open Access article distributed under the terms of the Creative Commons Attribution License (http://creativecommons.org/licenses/by/2.0), which permits unrestricted use, distribution, and reproduction in any medium, provided the original work is properly credited. 
their creativity and developing inventions. This resonates with thinking derived from innovation literature (Akintoye et al. 2012). As a result, designers and engineers in particular have seemingly lost their ability to innovate. This is partly attributable to 'inappropriate' education that has historically focused on production, rather than creativity. This is just the opposite of what happened in the $19^{\text {th }}$ and early $20^{\text {th }}$ Centuries, when designers and engineers were seen as the true 'drivers' of change. During this time, highlevel education was aligned to incentives (e.g. the highest salary rates) which helped design and engineering schools attract the most talented students; and these graduates were capable of meeting all technological and sociocultural challenges of the quickly expanding societies (Arciszewski 2006; Arciszewski and Harrison 2010a, 2010b; Arciszewski and Rebolj 2008). For instance, the construction of some monumental buildings during this period in history (e.g. Eiffel Tower, Villa Savoye, and The Bauhaus Building) created not only technological solutions, but also cultural revolutions- leading to a fundamental change in the way design and engineering was perceived.

This research posits that creativity has increasingly been underrepresented; and as such, needs to be revisited, especially in a rapidly evolving technological-driven world. For example, such challenges now include environmental and sustainability demands, increased levels of safety compliance, enhanced security issues, and whole life demands (energy, maintenance etc.). Whilst it could be argued that some of these challenges extend beyond the AEC domain per se, it is important to identify the key promoters and inhibitors of engineering creativity. In doing so, the profession as a whole will benefit from a new cogent way of embedding creativity into solutions; the result of which will not only benefit society, but also help inspire future AEC successors to follow this approach. Any changes, particularly those related to the ways that AEC students are educated, are extremely difficult, mostly because of the Vector of Psychological Inertia (G. Altshuller 1984) in action. This phenomenon refers to a natural tendency of individuals and communities to resist any changes, thereby delaying progress as much as possible. This is also influenced by the way in which the instructors were originally educated (mostly as highly sophisticated analysts) as this has a significant impact on the way they want to teach students. Cognisant of this, it is important to recognise the need to apply a complex systems approach to analyse the impact of this in order address the current situation.

This paper presents design and engineering leadership as three interrelated abilities: 1) to develop a vision, 2) to transform it into a strategy, and 3) to implement it. The key to leadership is the ability to develop feasible ideas or concepts (e.g., a new type of engineering system or construction process) using a set of abilities (traits) required to implement them [as opposed to using existing concepts to perform typical/routine work]. In particular, the development of a vision similar to conceptual design, to inventive design. In both cases a new idea, or a concept of an engineering system, needs to be developed. This is the area of activities in which creativity, or abductive generation of new ideas, takes place. This position is proffered, as historically, 'followers' have been seen to create stagnation, producing what has been called "Vector of Psychological Inertia" (H. Altshuller 1984), or fixation (Youmans and Arciszewski 2014). This psychological phenomenon therefore tends to makes change and progress more difficult, and in some cases often even prevents it. The emphasis therefore is to consider the development of leaders (not followers), in order to minimise the negative impact of the Vector of Psychological Inertia.

Building upon the principles of the Theory of Successful Intelligence (Sternberg 1985, 1996, 1997), this paper describes "Success" as a relative concept, which is defined by a given person in relation to the socio-cultural context and personal desires. This study therefore posits that there is a need to develop a new paradigm that recognises the importance of both analytical and creative works. Given this, this research defines analyst learners as the people who use rote learning and deduction, eventually induction, as opposed to creative people who use also abduction for reasoning. This approach extends learning capability beyond the learners' cognitive capability. Relying on the principles of Theory of Successful Intelligence (Sternberg 1985, 1996, 1997), Positive Psychology (Schueller 2012), and Appreciative Intelligence (Barrett and Fry 2008), this paper asserts that by using the 'right' methodologies and media, general principles of creative work could be translated into an explicit knowledge form and become part of a body of knowledge; hence, enabling the "Successful Departments" (Arciszewski 2009) to teach learners the "Creative Intelligence" and "Appreciative Intelligence". In this context, the potential of utilising advanced visualisation tools such as immersive game-like virtual reality interfaces is deemed vital - especially for augmenting analytical and parametric thinking capacity to intuitive idea generation (which could both be supported by these interfaces).

\section{Theory of successful intelligence}

The Theory of Successful Intelligence (Sternberg 1985, $1996,1997)$ is a major step toward understanding how individuals' abilities are interrelated with their life success. In the context of design and engineering education, this theory presents a new understanding of how education can be conceptualised, designed, and delivered. Through this theory, successfully intelligent people are 
defined as those being able to achieve their goals by leveraging their strengths, by compensating for their weaknesses, and those able to adapting to, shape, and select environments that will facilitate their success. This theory is underpinned by three fundamental pillars:

1. Successful intelligence can be learned;

2. Successful intelligence is a combination of three independently acquirable abilities, namely: practical intelligence, analytical intelligence, creative intelligence;

3. Successful intelligence is dynamic; both the criteria of success and the abilities the individual employs (i.e. the relative combination of the three intelligences) to achieve success may change during one's life-time.

In accordance with this theory, practical intelligence is an ability to solve simple everyday problems, and this is achieved using readily available knowledge and heuristics. Abilities to open a door or to ride a bus are good examples of practical intelligence. Analytical intelligence is an ability to solve analytical problems, and that requires using deductive skills and utilising existing knowledge (for example, analysis of traffic flow, numerical optimization, or planning a typical construction process, etc.). Analytical intelligence is acquired through the combination of rote learning and learning deductive skills. Analytical intelligence alone is what traditional IQ tests measure. In addition, traditional engineering education emphasizes analytical intelligence almost entirely. However, the Theory of Successful Intelligence stipulates that a balance of the three intelligences is absolutely necessary for life success, including professional success.

In the AEC context, creative intelligence is the ability to solve inventive problems, which require abductive skills and obviously the use of existing knowledge. Solving such problems requires development of unknown solutions or ideas, e.g. development of a new type of a wind bracing system in a tall building or a new type of a tunnel. Creative intelligence is acquired through the combination of rote learning with learning of both deductive and abductive skills.

\section{The Medici effect}

Johansson (2004) proposed two interrelated concepts of the "Medici Effect" and of the "Intersection". These concepts identify mechanisms driving an environment facilitating and stimulating emergence of transdisciplinary knowledge, which is the foundation of creativity in engineering. Transdisciplinary knowledge is a body of integrated knowledge with roots in two or more domains, but knowledge which is domain-independent. For this reason, both concepts are important for engineering educators who should recreate them when educating creative engineers.

The Medici Effect (Johansson 2004) was a mechanism driving the emergence of the Renaissance intellectual foundation. It was named after the Medici family, which lived in Florence, Italy, in the $15^{\text {th }}$ Century. The Medicis were one of the richest families in Europe, and sponsored many artists and scientists who were members of their court. Ultimately, members of the community began developing understanding of knowledge from outside of their domains. That led to new understanding of individual disciplines and to gradual emergence of the transdisciplinary knowledge. This knowledge became the intellectual foundation of the Renaissance.

The Intersection (Johansson 2004) is a product of the Medici effect. Johansson (2004) argued that Intersection is a time and place specific integration of knowledge with elements coming from various disciplines, cultures, and personalities. When a new concept is developed within a given discipline, it usually follows the existing line of evolution (Zlotin and Zusman 2006) and is considered directional. However, when an intersection occurs, a new idea represents a radical change, or beginning of a new line of evolution. Such an idea can be called "intersectional idea". Intersection can be described as knowledge integration with knowledge coming from two or more domains and resulting in transdisciplinary knowledge, valid in all contributing domains (Sage 2000).

The Medici Effect should be used in AEC education to create an educational environment, called by Arciszewski (2009) "Successful Department". Such an environment should be not only supporting but also stimulate teaching and learning engineering creativity. This is a way to reconstruct an environment critical for the emergence of the Renaissance; and more importantly, for the creation of an environment necessary to educate creative designers and engineers.

\section{Da Vinci's Principles}

Gelb $(1998,1999,2004)$ introduced the term "Da Vinci Seven Principles" and proposed seven principles describing the core characteristics of Da Vinci's approach to science, design and engineering. These seven principles which are shown in an artist's vision in (Figure 1) are as follows:

Principle No. 1, "Curiosita, means in Italian "curiosity." According to Gelb (2004), this da Vincian represents a curious and open attitude and a life-long learning accomplished by constantly asking questions about everything. Unfortunately, mostly analytical current educational materials gradually destroy Curiosita (Arciszewski 2014). In order to educate creative designers and engineers, it is necessary to not only maintain their Curiosita, but also expand it. The challenge here is to teach students the 


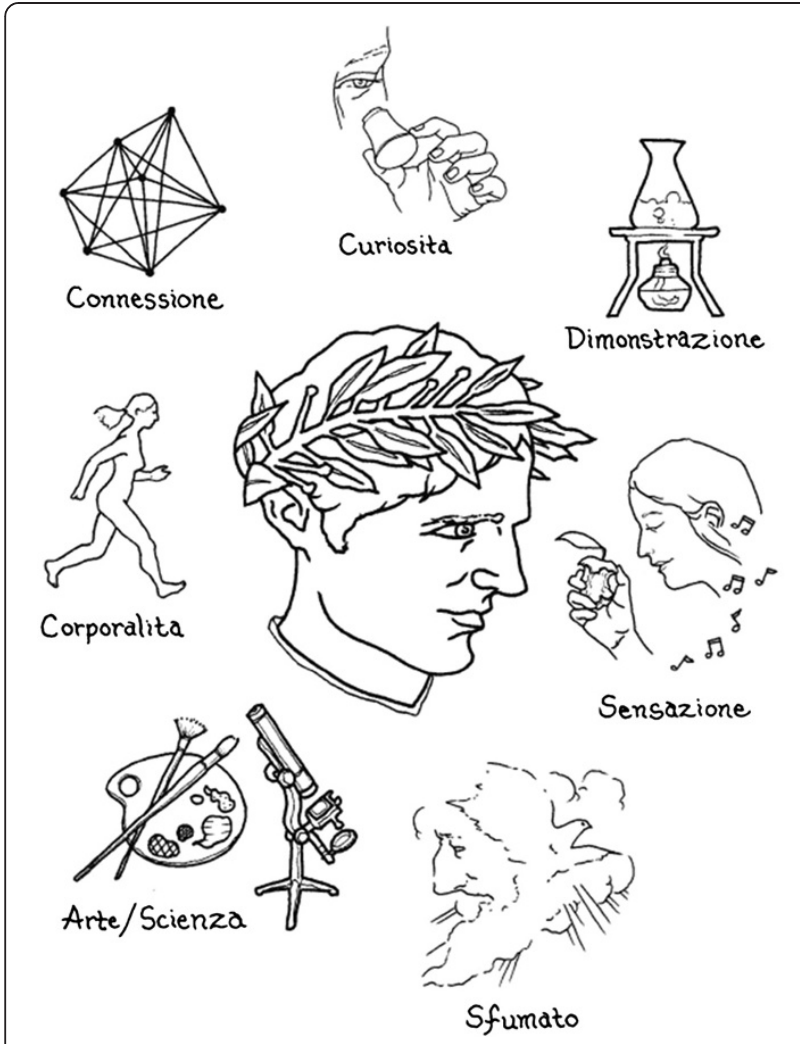

Figure 1 Da Vinci Seven Principles, Source: (Arciszewski 2009).

practical and analytical intelligence and at the same time expand their Curiosita, which is the key to the creative intelligence.

Principle No. 2, "Dimostrazione", means in Italian "demonstration". Gelb (2004) explained it as a unique attitude of experimentally verifying acquired knowledge. The Renaissance concept of apprenticeship is a good example of Demonstration in education. It was a combination of individual studies with extensive hands-on experience resulting in experiential learning. In this case, a master/teacher provides only guidelines and helps students how to learn on their own.

Principle No. 3, "Sensazione" means in Italian, "sensitivity to feelings". Gelb (1998) used this term to identify a complex attitude. It is development of all senses, practicing both the rational/intellectual and emotional approaches to life, and problems, integration of all abstract and physical inputs to create synaesthesia. It is a complex emotional state when an artist or a scholar is fully engaged in solving a problem, both intellectually and emotionally - using all his/her senses as using synaesthesia to acquire transdisciplinary knowledge or to create new ideas. Sensazione can be also interpreted as a practicing "whole-brain thinking" in which focus is on the emotional dimension of our cognition ultimately leading to a much more complete understanding of the world, of our environment, and of ourselves, including our consciousness and ability to transform it.

Principle No. 4, "Sfumato," means in Italian "turn to mist"; or in the case of colours, "soft," or "mellow." Gelb (1998) interpreted Sfumato as a willingness to accept and to understand the world in its infinite complexity. It also means keeping an open mind in the face of unknown and of uncertainty, a willingness to embrace contradictions, and paradoxes, and acquiring, accepting and using ambiguous knowledge. Sfumato is a surprisingly modern notion. In the case of knowledge discovery and inventive problem solving such processes are known today as lengthy and having subsequent periods of conscious and subconscious activities. To produce inventions, all kinds of input are obviously desired in order to activate and use the entire power of the human brain, both the analytical left hemisphere and the creative right side.

Principle No. 5, "Arte/Scienza" means that a Renaissance person should be a "Whole-Brain Thinker". People should develop an understanding of the world using two entirely different but complementary perspectives with roots in art and science, respectively. These two perspective should be balanced since both are necessary but neither sufficient. If AEC educators are interested in creating an education producing inventors, then the Principle "Arte/Scienza" is very important. It represents a significant departure from the traditional engineering education nearly entirely focused on the rational, "scientific" approaches and knowledge.

The Principle No. 6, "Corporalita" means "the state of being in physical or bodily form rather than spiritual form" in accordance to MSN Encarta. It is incomplete, if not simply wrong description of the Da Vinci's Principle No. 6. The attitude of Corporalita is much more complex. It is described by Gelb (1998) as "Means sana in corpora sano" - sound mind in a sound body. Da Vinci argued that a human being should carefully maintain a balance between the intellectual and physical development in order to realize his/her full potential. It was also a reflection of the Renaissance belief that a genius must be physically superior with respect to ordinary people. Corporalita is particularly important for designers and engineers. They need to maintain a balance between body, mind, and spirit, but also to attain a relatively high level of physical fitness to survive long hour of climbing stairs and ladders on a construction site.

Principle No. 7, "Connessione" means in Italian "connection", however this principle in fact means recognition of interconnectedness of all things and phenomena in nature and life, the world is a single system with its all elements connected by direct and indirect feedbacks, the world is a complex and chaotic system, knowledge is a non-linear system. Only recently, in the second half of 
the $20^{\text {th }}$ Century, the science of holistic understanding of the world, called "Cybernetics" emerged. It gradually led to the development of the "Systems Analysis" based on the principle of wholeness in its approach to analysis of all systems, built and natural, real and abstract, small and large. Therefore, "Connessione" may be interpreted as a systems view of the world.

\section{Methods}

\section{Successful education}

Successful Education (Arciszewski 2009) is a new paradigm in design and engineering education. This paradigm was inspired by the latest developments in the modern cognitive psychology, especially by the Theory of Successful Intelligence (Sternberg 1985, 1996, 1997). This paradigm has also been strongly influenced by a new understanding of historical and social mechanisms behind the emergence of the Renaissance, including the Medici Effect (Johansson 2004) and the Da Vinci Principles (Gelb 1998, 1999, 2004). (Arciszewski (2009)) argued that Principles are particularly important because they provide a synthesis of all attitudes practiced by Da Vinci and by the other great Renaissance engineers.

In this paradigm, the key concept is "Successful Designers and Engineers" and it describes the designers and engineers who have acquired as students not only the necessary and sufficient body of knowledge to practice engineering, but also learned Successful Intelligence including its all three components, i.e. practical, analytical, and creative intelligence. Such graduates are prepared to not only undertake any kind of routine work, but, if necessary, also prepared to become inventors and leaders, since in both cases the key to success is an ability to develop new ideas.

In Table 1, Successful Education is compared with a past design and engineering education paradigm, called "Master-Apprentice Paradigm", and the present one, called by us "Scientific Paradigm". The comparison is done from the perspective of the Theory of Successful Intelligence and of its three main components. In this context, only Successful Education is complete since only it addresses all three components of Successful Intelligence and consequently creates an opportunity to educate successful engineers.

Successful Education requires not only a new understanding of design and engineering education priorities

Table 1 Comparison of teaching paradigms

\begin{tabular}{llll}
\hline Teaching paradigm & $\begin{array}{l}\text { Practical } \\
\text { intelligence }\end{array}$ & $\begin{array}{l}\text { Analytical } \\
\text { intelligence }\end{array}$ & $\begin{array}{l}\text { Creative } \\
\text { intelligence }\end{array}$ \\
\hline Master-apprentice & Yes & Yes \\
Scientific & Yes & Yes & \\
Successful education & Yes & Yes & Yes \\
\hline
\end{tabular}

and several new or modified courses, it also requires a complex environment, called "Successful Department", which will enable and stimulate the creation of successful engineers. A modern Medici Effect and the resulting intersection of ideas are crucial for the learning process. Therefore, they require a revolutionised environment (in terms of intellectual and technological structures) which is completely different that the current look of so many design and engineering departments. In essence, there are four major components of a Successful Department, namely courses, instructors, physical environment, and ambience (Arciszewski 2009). This is aligned with Salama's (2008) "Integrating Knowledge in Design Education" theory which argues that a responsive architectural design pedagogy giving credit to socio-cultural, and environmental needs can enable future architects to create livable environments.

Traditional, analytical courses are absolutely necessary for the future successful engineers, although they are grossly insufficient for them. They require additional courses on Inventive Design and Engineering, i.e. focused on the emerging science of inventive problem solving. For the best results, such courses could/should be offered to students through their entire period of studies. A single course for seniors (the present practice at George Mason University) is a step in the right direction, but it comes too late to impact learning in other courses and to transform students into successful engineers. A much better solution is a sequence of several courses, even if the total number of credit hours is the same.

Instructors are the key component of a Successful Department. A faculty in academic units are surprisingly similar in many aspects (ergo birds of feather flock together) despite all efforts to create diversity, which is often imposed only for political reasons. A successful Department requires, however, a true diversity, which may be described as "balanced intersection". This term is understood as a selection of instructors resulting in a department in which cultural backgrounds of instructors are strongly differentiated, they represent both applied and fundamental research, have experience in analytical and exploratory research and they represent various thinking styles.

Physical environment creates a framework for learning and also send a message about the nature of a given academic unit (Hou and Ji 2010). An ideal urban design for a Successful Department should be based on the concept of the agora, as an ideal form stimulating human interactions through complex socio-psychological mechanisms. Such an urban complex should have several buildings, arranged around the central square/agora. A building should be dedicated to teaching practical intelligence and designed with all kinds of testing laboratories and 
workshops. Another building should be dedicated to teaching analytical intelligence and it should have various computer laboratories. A third building, "Inventors Heaven", a must, should be dedicated to teaching creative intelligence with appropriately selected laboratories and workshops specifically designed for teams working on their inventive challenges. Finally, there should be an administrative building for faculty and classrooms.

A Successful Department would never be fully effective without a proper ambience. In this case, ambience is understood as a multi-sensory experience that positively affects students, faculty, and staff helping them to learn or teach in the best way to create successful engineers. Ambience obviously has an emotional dimension, which distinguishes it from a traditional department. Ambience is a reflection of people's perception of an environment surrounding them and can be carefully created in such a way as to contribute successful designers and engineers. Arciszewski (2009) discussed various components of ambience in a Successful Department, e.g. guiding principles and stories, colours, music, art, various activities, and even the proper lighting in the Successful Department.

Building upon the theoretical bases discussed in the theory of Successful Education (Arciszewski 2009), this paper highlights the potentials of the advanced IT interfaces for leveraging all four components of such a Successful Department. The paper particularly suggests use of advanced game-like virtual workspaces in order to leverage education of successful designers and engineers for the AEC professions.

\section{Games and virtual reality in construction engineering education}

The nature and complexity of communication mechanisms within the Architecture, Engineering, and Construction (AEC) projects has changed significantly over the last ten years, especially the modus operandi and integration with core business operations. This has been reflected through the increased prevalence, use, and deployment of web-based project collaboration technologies and project extranets. Within the AEC sector, Information and Communications Technology (ICT) has revolutionised production and design (Cera et al. 2002), which has led to dramatic changes in terms of labour and skills (Fruchter 1998). However, it is also important to acknowledge that the capabilities of such applications (and implementation thereof) in predicting the cost and performance of optimal design proposals (Petric et al. 2002) should enable design engineers to compare the quality of any one tentative solution against the quality of previous solutions. This was further reinforced by Goulding et al. (2007), regarding the ability to experiment and experience decisions in a 'cyber-safe' environment in order to mitigate or reduce risks prior to construction. It is therefore crucial for the AEC industry to employ cutting-edge ICT technologies to issues related to organisational management and decision making (Friedman 2005). Furthermore, whilst advocates note that these have helped to resolve some of the aforementioned challenges, Pour Rahimian et al. (2011) noted that project teams are still facing real and signification problems and challenges regarding heterogeneous systems faced by project teams using project extranets. In this essence, the problem here is that the industry is experiencing confusion as to how to manage project information in order to support decision-making processes. This is the point where Fruchter (2004) suggested the digital integration of the whole data creation, retrieval, and management system within building industry in order to prevent tacit knowledge loss and miscommunication among various parties from different disciplines. In this respect, recent innovation in Virtual Reality (VR) technologies and AEC decision- support toolkits have now matured, enabling tele-presence engagement to occur through integrated collaborative environments. Several opportunities are now available, including significantly improved immersive interactivity with haptic support that can enhance users' engagement and interaction.

Employing cutting edge ICT tools is also expected to leverage training systems within the AEC sector (Fruchter 1998) as the implementation of effective training could make impact on the whole industry by addressing and fulfilling the needs of the different stakeholders in the industry. In this respect, advanced ICT systems are expected to address the shortcomings of 'typical' learning models that often provide the trainees with only general instructions (Laird 2003) and issues associated with unaffordable costs of the 'traditional' on -the-job trainings (Clarke and Wall 1998). Therefore, new ICT advancements that incorporate innovative proactive experiential learning approaches which link theory with practical experience, using Virtual Reality interactive learning environments can be especially effective (Alshawi et al. 2007). This research builds upon the findings of previous studies in this area and links them to the principles of Successful Education (Arciszewski 2009), with specific emphasis on supporting the decision-making process at the construction stages. The study provides a novel approach of applying Game Theory to non-collocated design teams using Game-Like VR environments blended to Social Sciences Theory (social rules) and Behavioural Science Theory (Decision Science/Communication Science). In essence, the aim of this study is to advocate the advantages of applying flexible, interactive, safe learning environment for practicing new working conditions with respect to offsite production (OSP) in general, and Open Building Manufacturing (OBM) in particular; without the 'do-or-die' consequences often faced on real construction projects (Goulding and Rahimian 2012). 
As the underpinning technology, VR has been defined as a $3 \mathrm{D}$ computer-generated alternative environment to be immersed in, for navigating around and interacting with (Briggs 1996), or as a component of communication taking place in a 'synthetic' space, which embeds human as its integral part (Regenbrecht and Donath 1997). The definitions of VR systems usually includes a computer capable of real-time animation, controlled by a set of wired gloves and a position tracker, and using a head-mounted stereoscopic display as visual output. For instance, Regenbrecht and Donath (1997) defined the tangible components of VR as a congruent set of hardware and software, with actors within a three-dimensional or multi-dimensional input/output space, where actors can interact with other autonomous objects, in real time. VR has also been defined as a simulated world, which comprises of some computer-generated images conceived via head mounted eye goggles and wired clothing thereby enabling the end users to interact in a realistic three-dimensional situation (Yoh 2001).

Over the last 30 years, ICT systems have matured and enabled construction organisations to fundamentally restructure and enhance their core business functions. A. Z. Sampaio and Henriques (2008) asserted that the main objective of using ICT in construction field is supporting management of digital data, namely to convert, store, protect, process, transmit, and securely retrieve datasets. They acknowledge the commencement of VR techniques as an important stepping stone for data integration in construction design and management as they are capable of holding and presenting the whole information about buildings (e.g. size, material, spatial relationships, mechanical and electrical utilities, and etc.) through a single output. Similarly, Zheng et al. (2006) proposed the use of VR to reduce time and costs in product development and to enhance quality and flexibility for providing continuous computer support during development lifecycle.

Early studies that incorporated VR into the design profession used it as an advanced visualisation medium. Since as early as 1990, VR has been widely used in the AEC industry as it forms a natural medium for building design by providing $3 \mathrm{D}$ models, which can be manipulated in real-time and used collaboratively to explore different stages of the construction process (Whyte et al. 1998). It has also been used as a design application to provide collaborative visualisation for improving construction processes (Bouchlaghem et al. 2005). However, expectations of VR have changed during the current decade. According to A.Z. Sampaio and Henriques (2008), it is increasingly important to incorporate VR $3 \mathrm{D}$ visualisation and decision support systems with interactive interfaces in order to perform real-time interactive visual exploration tasks. This thinking supports the position that a collaborative virtual environment is a $3 \mathrm{D}$ immersive space in which 3D models are linked to databases, which carry characteristics. This premise has also been followed through other lines of thought, especially in construction planning and management by relating $3 \mathrm{D}$ models to time parameters in order to design 4D models (Fischer and Kunz 2004), which are controlled through an interactive and multi-access database. In similar studies, 4D VR models have been used to improve many aspects and phases of construction projects by: 1) developing and implementing applications for providing better communication among partners (Leinonen et al. 2003), 2) supporting design creativity (Rahimian and Ibrahim 2011), 3) introducing the construction plan to stakeholders (Khanzade et al. 2007), and, 4) following the construction progress (Fischer 2000).

With regards to education, Wellings and Levine (2010) posited that there was a need to redesign the current text-based lessons into collaborative and multidisciplinary problem-based materials, expressly to take on board real world problems and solutions. They argued that this was not possible unless immersive and interactive games were employed for improving trainees' engagement. Similarly, Thai et al. (2009) asserted that pedagogical digital games offered an intact opportunity to enhance engagement of trainees and revolutionise teaching and learning. ACS (2009) summarised the benefits of the emerging educational interactive immersive game environments: 1) annotated objects could provide deeper level of knowledge on demand, 2) incorporating additional dimensions of subjects $(\mathrm{nD}), 3)$ supporting distance team collaboration, 4) leveraging equal opportunities by providing distance learning opportunities and, 5) simulated learning by modelling a process or interaction that closely imitates the real world in terms of outcomes.

VR applications and game engines are now increasingly being used in the teaching and learning AEC. According to Zudilova-Seinstra et al. (2009), VR as a teaching tool can contribute to the trainees' professional future by developing some learning activities beyond what is available in the conventional training systems. With respect to educational issues in the AEC industry, A. Z. Sampaio et al. (2010) argued that the interaction with $3 \mathrm{D}$ geometric models can lead to active learner thoughts which seldom appear in conventional pedagogical conditions. Moreover, Juárez-Ramírez et al. (2009) asserted that when augmented to 3D modelling, VR could lead to better communication in the process of AEC training. However, VR training environments have arguably not yet fully reached the potential of reducing training time, providing a greater transfer of expert knowledge; or supporting decision making. This was primarily down to the ways in which this technology was augmented. It is therefore argued that educational training tools need to 'engage' learners by putting them in the role of decision makers and 'pushing' 
them through challenges; hence, enabling different ways of learning and thinking through frequent interaction and feedback, and connections to the real world context (Goulding et al. 2007). Furthermore, it is postulated that paring instructional content with game features, could engage users more fully, hence, help to achieve the desired instructional goals. In this respect, this study applied an input-process-output model (Garris et al. 2002) of instructional games and learning to design an instructional program which incorporated certain features or characteristics from gaming technology; which trigger a cycle that includes user judgment or reactions, such as enjoyment or interest, user behaviour such as greater persistence or time on task, and full learner feedback (Figure 2).

\section{Results and discussion}

This section presents the developed Game-Like Virtual Reality Construction-Site Simulator (GVRSS) in this study. The aim of the developed GVRSS was to embrace 'real life' issues facing offsite construction projects in order to appeal to professionals by engaging and challenging them to find 'real life' solutions to problems often encountered on site. Given this, a real construction project was used to govern the authenticity of the learning environment. In this context, the prototype learning simulator was designed specifically to allow 'things to go wrong', and hence, allow 'learning through experimentation' or 'learning by doing'. In this respect, although the 'scenes' within the simulator take place on a construction site, the target audience was focussed primarily on construction professionals e.g. project managers, construction managers, architects, designers, commercials, suppliers, manufacturers etc. Thus, the construction site was used as the main domain through which all the unforeseen issues and problems (caused through upstream decisions, faulty work etc.) could be enacted. The key learning impact areas were to acknowledge the importance, significance and real implications of time, cost, resources etc. Learning was planned and reinforced through a debriefing session, where learners were able to demonstrate additional understanding, particularly with respect to mitigating such issues in future construction projects. In this context, learning occurred through the following:

- Learner autonomy - to make all decisions;

- Interactivity - environment provides feedback on the decisions taken, and their implications on the overall project (cost, time, resources, health and safety, etc.);

- Reflection - users are able to defend decisions on the feedback provided, and have the ability to identify means to avoid/mitigate potential problems in the future.

In essence, the main concept of the simulator was based on its ability to run scenarios through a VR environment to address predefined training objectives. In this respect, learning was designed to be driven by problems encountered in this environment, supported by a report critique on learners' choices, rationale, and defence thereof. In accordance to these objectives, the GVRSS was designed and developed as an educational web-based simulation tool comprising of both non-immersive and immersive pages for providing construction managers (and other disciplines) the opportunity to experience challenges of reallife AEC projects through simulated scenarios. In order to minimise interruption on the learners' reasoning process, the Graphical User Interface (GUI) was designed to be as simple and straightforward as possible with respect to data input. Thereby, the interface was designed as to be accessible through any standard web browser to provide users with login account details and other criteria, e.g. selection of available construction sites, projects, contractors, equipment, scenarios etc. All choices made by 'players' as well as their registration data was automatically recorded in a MySQL database, which was also accessible through the immersive application for project simulation. After completing the initial decision-making process through the interactive ASP. Net Web Forms, learners are able to commence the training session, starting with a

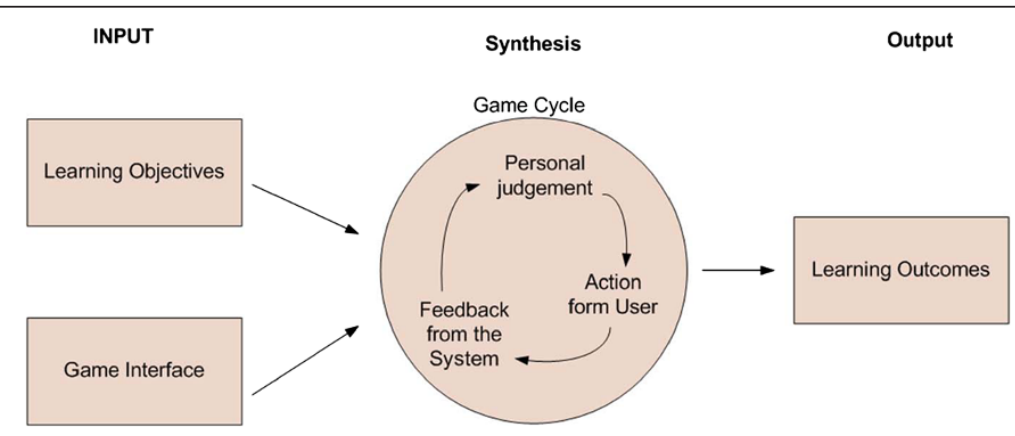

Figure 2 Educational game model input-synthesis-outcome (Garris et al. 2002). 


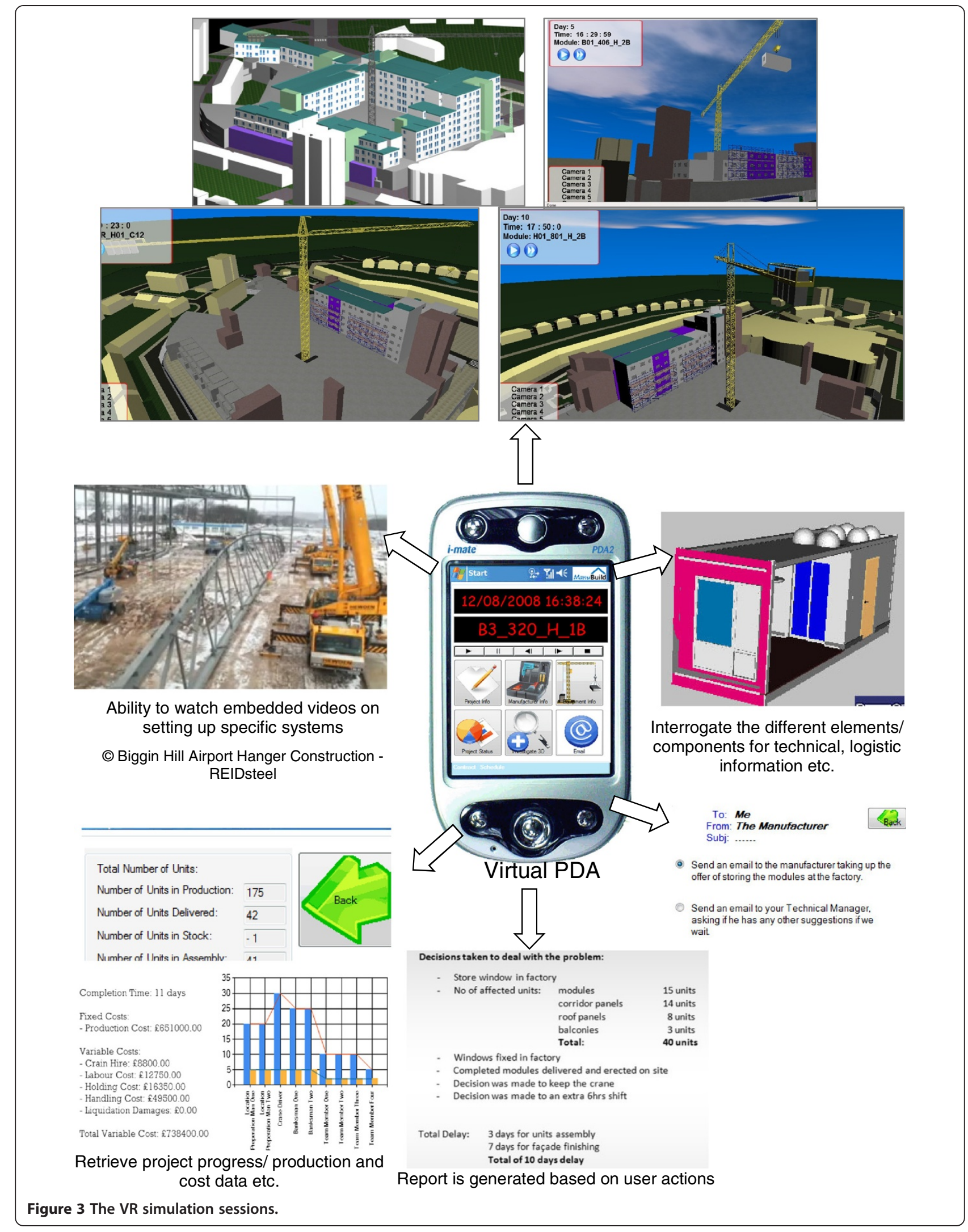


'walkthrough' to experience and appreciate the complexity of the project. At this stage, the application provides users with a summary of the project and contract, and runs the simulation of the project within an immersive and interactive environment developed in Quest $3 \mathrm{D}^{\mathrm{Tm}} \mathrm{VR}$ programming Application Programming Interface (API).

Within the simulated Quest3D environment, the users are able to experience the outcomes of all decisions made. They are also challenged by unexpected events designed according to the selected scenario, and are required to make decisions for dealing with these issues. The monitoring and communication tools are embedded in different parts of the main interface as well as the facilitated standard embedded virtual PDA or smart phone-type interface, which appears when required. The simulator ultimately records and tracks the users in the database and navigates to the conclusion page to reveal all scores of the user (together with the logic behind the marking procedure). Figure 3 illustrates a selection of the various functions available to the user of the simulator to fully interact with and retrieve information from the simulator during the VR simulation session. Further inclusion of the whole tree is considered for the exploitation phase.

\section{Conclusions}

Construction projects are increasingly becoming more complex, often engaging new business processes and technological solutions to meet ever-increasing demands. These business demands are complex and multifarious; often requiring the conjoining of high level skill sets to deliver the solutions needed. These skill sets are currently underrepresented, and seldom engage the collective ethos needed to envelop creative thinking, through such approaches as Successful Intelligence in order to create new innovative solutions. It is therefore paramount that the industry as a whole engages the right type (and level) of skill sets and competence needed to meet these project requirements and business imperatives. Acknowledging this, it is also important the causal drivers and influences associated with creativity and successful decision-making in global AEC teams are fully understood and supported. This however, requires a radical review in the way educational programmes and systems are designed and delivered. For example, with respect to leveraging creativity and delivering innovation, this study reflected on the Renaissance period and the creativity-oriented learning/ teaching paradigm called "Master-Apprentice Paradigm", as opposed to the current analysis focused "Science Paradigm". The Medici Effect and the related phenomenon of intersection and seven $\mathrm{Da}$ Vinci Principles have been acknowledged as being able to revolutionise modern design and engineering education. This study then introduced the theory of Successful Intelligence and its three components as an underpinning platform for educating a new generation of designers and engineers.

The "Successful Education" paradigm (Arciszewski 2009) was presented as a new approach for educating AEC professionals was presented, including the concept of a new educational environment; the need for a new combination of courses that focus on teaching the three kinds of Successful Intelligence (in the context of AEC sector); including guidelines of how to properly select instructors that are capable of implementing such approach. A proofof-concept prototype that uses a game-like virtual reality (VR) visualisation interface supported by Mind Mapping was presented as an exemplar, to demonstrate how the proposed approach could be implemented. The developed simulator offers a risk free environment where learners can evaluate how decisions they make affect their business. This includes (but is not limited to) analysing issues occurring on the construction site, such as: design concerns, process conflicts, logistics challenges, and supply chain issues etc.

This paper proffers that enhanced engagement through an immersive project environment could lead to a better understanding of the real-life AEC problems. This can be achieved by placing learners in a cyber-safe environment; specifically to leverage learners' cognitive processes to real-world issues. This study supports a novel approach of applying Game Theory to non-collocated design teams using Game-Like VR environments blended to Social Sciences Theory (social rules) and Behavioural Science Theory (decision science/communication science). This can address the need to evaluate actor involvement in order to reveal new insight into AEC organisational behaviour and the social constructs that often affect decision making. In this paper, advanced VR training and simulation tools were proffered through an exemplar in order to highlight the possibilities available, especially as this forms a conduit for aligning pivotal drivers to achieve specific learning outcomes. Future research in this area is likely to embrace the importance of pedagogy (learner styles/traits), as this has been openly acknowledged as being particularly efficacious and instrumental for delivering training material to specific learner-types.

\section{Competing interest}

All authors declare that they have no competing interests.

\section{Authors' contributions}

TA developed the theory of Successful Education. JS Goulding developed the case study of Game-Like Virtual Reality Construction-Site Simulator. FPR carried out further programming and coding for extending the Game-Like Virtual Reality Construction-Site Simulator in order to enable non-collocated AEC collaboration through this interface. All three authors worked on linking the principles of theory of Successful Education to the potentials of emerging VR interfaces. All authors read and approved the final manuscript.

\section{Author details}

${ }^{1}$ Centre for Sustainable Development, The Grenfell-Baines School of Architecture, Construction and Environment, University of Central Lancashire, 
Preston PR1 2HE, UK. ${ }^{2}$ Civil, Environmental and Infrastructure Engineering Department, Volgenau School of Engineering, George Mason University, Fairfax, Virginia, USA.

\section{Received: 13 January 2014 Accepted: 24 April 2014}

Published: 19 May 2014

\section{References}

ACS. (2009). 3D Learning and Virtual Worlds. An ACS: Expertise in ActionTM White Paper. http://www.trainingindustry.com/media/2043910/acs\%203d\%20worlds \%20and\%20virtual\%20learning_whitepaper\%20april\%202009.pdf, Access Date, 22/02/2014

Akintoye, A, Goulding, JS, \& Zawdie, G (Eds.). (2012). Construction Innovation and Process Improvement. London: Wiley-Blackwell.

Alshawi, M, Goulding, JS, \& Nadim, W. (2007). Training and Education for Open Building Manufacturing: Closing the Skills Gap. In AS Kazi, M Hannus, S Boudjabeur, \& A Malon (Eds.), Open Building Manufacturing: Core Concepts and Industrial Requirements. Helsinki, Finland: ManuBuild in collaboration with VIT - Technical Research Centre of Finland.

Altshuller, G. (1984a). Creativity as an Exact Science. New York: Gordon and Breach, Science Publishers, Inc.

Altshuller, H. (1984b). Creativity as an Exact Science. New York: Gordon and Breach, Science Publishers, Inc.

Arciszewski, T. (2006). Civil Engineering Crisis. ASCE Journal of Leadership and Management in Engineering, 6(1), 26-30.

Arciszewski, T. (2009). Successful Education. How to Educate Creative Engineers. Fairfax, VA: Successful Education LLC.

Arciszewski, T. (2014). Future of engineering education. Proceedings of the ICE Management, Procurement and Law, 167(1), 46-59.

Arciszewski, T, \& Harrison, C. (2010a). Successful Civil Engineering Education. ASCE Journal of Professional Issues in Engineering Education and Practice, 136(1), 1-8.

Arciszewski, T, \& Harrison, C. (2010b). Successful Education: The Key to Engineering Creativity (Paper presented at The International Conference on Computing in Civil and Building Engineering). Nottingham, UK: Nottingham University Press.

Arciszewski, T, \& Rebolj, D. (2008). Civil Engineering Education: Coming Challenges. International Journal of Design Science and Technology, 14(1), 53-61.

Barrett, FJ, \& Fry, RE. (2008). Appreciative Inquiry: A Positive Approach to Building Cooperative Capacity. Chagrin Falls, OH: Taos Institute.

Bouchlaghem, D, Shang, H, Whyte, J, \& Ganah, A. (2005). Visualisation in architecture, engineering and construction (AEC). Automation in Construction, 14(3), 287-295.

Briggs, JC. (1996). The Promise of Virtual Reality. The Futurist, 30, 30-31.

Cera, CD, Reagali, WC, Braude, I, Shapirstein, Y, \& Foster, C. (2002). a Collaborative 3D Environment for Authoring Design Semantics. Graphics in Advanced Computer-Aided Design, 22(3), 43-55.

Clarke, L, \& Wall, C. (1998). UK construction skills in the context of European developments. Construction Management and Economics, 16(5), 553-567.

Fischer, M. (2000). 4D CAD-3D models incorporated with time schedule, CIFE Centre for Integrated Facility Engineering in Finland, VTT-TEKES, CIFE Technical Report, Helsinki. Finland: University of Helsinki Press.

Fischer, M, \& Kunz, J. (2004). The Scope and Role of Information Technology in Construction. CIFE Technical Report (p. 19). San Francisco: Center for Integrated Facility Engineering, Stanford University.

Friedman, TL. (2005). The World is Flat: A Brief History of the 21st Century. New York: Farrar, Straus and Giroux.

Fruchter, R. (1998). nternet-based Web Mediated Collaborative Design and Learning Environment, in Artificial Intelligence in Structural Engineering. In Lecture Notes in Artificial Intelligence (pp. 133-145). Berlin: Heidelberg: Springer-Verlag.

Fruchter, R. (2004). Degrees of Engagement in Interactive Workspaces. International Journal of Al \& Society, 19(1), 8-21. doi:10.1007/s00146-004-0298-x.

Garris, R, Ahlers, R, \& Driskell, JE. (2002). Games, Motivation, and Learning: A research and Practice Model. Simulation Gaming, 33(4), 441-467.

Gelb, MJ. (1998). How to Think like Leonardo da Vinci. New York: Random House.

Gelb, MJ. (1999). How to Think like Leonardo da Vinci, Workbook. New York: Random House

Gelb, MJ. (2004). Da Vinci Decoded: Discovering the Spiritual Secrets of Leonardo's Seven Principles. New York: Bantam Dell.

Goulding, JS, \& Rahimian, FP. (2012). Industry Preparedness: Advanced Learning Paradigms for Exploitation. In A Akintoye, JS Goulding, \& G Zawdie (Eds.),
Construction Innovation and Process Improvement (pp. 409-433). Oxford, UK Wiley-Blackwell.

Goulding, JS, Sexton, M, Zhang, X, Kagioglou, M, Aouad, GF, \& Barrett, P. (2007). Technology adoption: breaking down barriers using a virtual reality design support tool for hybrid concrete. Construction Management and Economics, 25(12), 1239-1250.

Hou, Y, \& Ji, L. (2010). Stimulating Design Creativity by Public Places in Academic Buildings. Journal Structure and Envirinment, 3(2), 5-13.

Johansson, F. (2004). The Medici Effect. Boston, MA: Harvard Business School Press.

Juárez-Ramírez, R, Sandoval, G, Cabrera Gonzállez, C, \& Inzunza-Soberanes, S. (2009). Educational strategy based on IT and the collaboration between academy and industry for software engineering education and training (Paper presented at the m-ICTE 2009, V International Conference on Multimedia and ICT's in Education). Lisbon, Portugal, Badajoz, Spain: FORMATEX.

Khanzade, A, Fisher, M, \& Reed, D. (2007). Challenges and benefits of implementing virtual design and construction technologies for coordination of mechanical, electrical, and plumbing systems on large healthcare project (Paper presented at the CIB 24th W78 Conference). Maribor, Slovenia: University of Maribor Press.

Laird, D. (2003). New Perspectives in Organisational Learning, Performance, and Change: approaches to training and development (3rd ed.). USA: Preseus Books Group.

Leinonen, J, Kähkönen, K, Retik, AR, Flood, RA, William, I, \& O'Brien, J. (2003). New construction management practice based on the virtual reality technology. In R. R. A. Issa, I. Flood, \& W. O'Brien (Eds.), 4D CAD and Visualization in Construction: Developments and Applications (pp. 75-100). Tokyo: AA Balkema Publishers.

NGRF. (2010). N. G. R. F. http://www.guidance-research.org/future-trends/ construction/info. Accessed 14th Aug 2010.

Petric, J, Maver, T, Conti, G, \& Ucelli, G. (2002). Virtual reality in the service of user participation in architecture (Paper presented at the CIB W78 Conference) Aarhus Denmark: Aarhus School of Architecture.

Pour Rahimian, F, Ibrahim, R, Wirza, R, Abdullah, MTB, \& Jaafar, MSBH. (2011) Mediating Cognitive Transformation with VR 3d Sketching During Conceptual Architectural Design Process. Archnet-IJAR, International Journal of Architectural Research, 5(1), 99-113.

Rahimian, FP, \& Ibrahim, R. (2011). Impacts of VR 3D sketching on novice designers' spatial cognition in collaborative conceptual architectural design. Design Studies, 32(3), 255-291.

Regenbrecht, H, \& Donath, D. (1997). Architectural Education and Virtual Reality Aided Design (VRAD). In D Bertol (Ed.), Designing Digital Space - An Architect s Guide to Virtual Reality (pp. 155-176). New York: John Wiley \& Sons.

Sage, AP. (2000). Transdisciplinarity Perspectives in Systems Engineering and Management. In MA Somerville \& D Rapport (Eds.), Transdisciplinarity: Recreating Integrated Knowledge (pp. 158-169). Oxford: EOLSS Publishers Ltd.

Salama, AM. (2008). A Theory for Integrating Knowledge in Architectural Design Education. Archnet-IJAR, International Journal of Architectural Research, 2(1), 100-128.

Sampaio, AZ, \& Henriques, PG. (2008). Visual simulation of previous termcivil engineeringnext term activities: didactic virtual previous termmodels (Paper presented at the WSCG 2008, 16th International Conference in Central Europe on Computer Graphics). Plzen, Czech Republic: Visualization and Computer Vision.

Sampaio, AZ, Ferreira, MM, Rosário, DP, \& Martins, OP. (2010). 3D and VR models in Civil Engineering education: Construction, rehabilitation and maintenance. Automation in Construction, 19(7), 819-828.

Schueller, SM. (2012). Positive Psychology. In VS Ramachandran (Ed.), Encyclopedia of Human Behavior (2nd ed., pp. 140-147). San Diego: Academic Press.

Sternberg, RJ. (1985). Beyond IQ: A Triarchic Theory of Intelligence. Cambridge: Cambridge University Press.

Sternberg, RJ. (1996). Successful Intelligence. New York: Simon \& Shuster.

Sternberg, RJ. (1997). A Triarchic View of Giftedness: Theory and Practice. In NN Coleangelo \& GA Davis (Eds.), Handbook of Gifted Education (pp. 43-53). Boston, MA: Allyn and Bacon.

Thai, AM, Lowenstein, D, Ching, D, \& Rejeski, D. (2009). Game Changer: Investing in digital play to advance children's learning and health. The Joan Ganz Cooney Center. http://www.joanganzcooneycenter.org/wp-content/uploads/2010/03/ game_changer_final_1_.pdf, Access Date: 06/06/2014.

Wellings, J, \& Levine, MH. (2010). The Digital Promise: Transforming Learning with Innovative Uses of Technology. A white paper on literacy and learning in a new media age, Joan Ganz Cooney Center at Sesame Workshop. http://dmlcentral. net/sites/dmlcentral/files/resource_files/Apple.pdf, Access Date: 06/06/2014. 
Whyte, J, Bouchlaghem, N, \& Thorpe, A. (1998). The promise and problems of implementing virtual reality in construction practice. In The Life-cycle of Construction IT Innovations: Technology Transfer From Research To practice (CIB W78), Stockholm, 3-5 June, 1998.

Yoh, M. (2001). The Reality of Virtual Reality. In Seventh International Conference on Virtual Systems and Multimedia (VSMM'01), Organized by Center for Design Visualization. Berkley, USA: University of California Berkley. IEEE. doi:0-7695-1402-2/01.

Youmans, R, \& Arciszewski, T. (2014). Design Fixation: Classifications and Modern Methods of Prevention. Artificial Intelligence for Engineering Design, Analysis and Manufacturing. in print.

Zheng, X, Sun, G, \& Wang, SW. (2006). An Approach of Virtual Prototyping Modeling in Collaborative Product Design (Paper presented at the CSCW 2005, LNCS 3865).

Zlotin, B, \& Zusman, A. (2006). Directed Evolution: Philosophy, Theory, and Practice. Southfield, Ml: Ideation International.

Zudilova-Seinstra, E, Adriaansen, T, \& van Liere, R. (2009). Trends in Interactive Visualization: State-of-the-Art Survey (Advanced Information and Knowledge Processing). London: Springer-Verlag.

doi:10.1186/2213-7459-2-4

Cite this article as: Pour Rahimian et al:: Successful education for AEC professionals: case study of applying immersive game-like virtual reality interfaces. Visualization in Engineering 2014 2:4.

\section{Submit your manuscript to a SpringerOpen ${ }^{\circ}$} journal and benefit from:

- Convenient online submission

- Rigorous peer review

- Immediate publication on acceptance

- Open access: articles freely available online

- High visibility within the field

- Retaining the copyright to your article

Submit your next manuscript at $>$ springeropen.com 